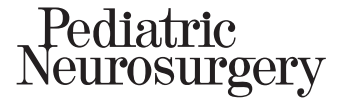

\title{
Changing Seasons
}

Neurosurgery is a complex and difficult-to-master medical specialty; how much more so is pediatric neurosurgery, where patients arrive with lifelong diseases that often make them rely heavily upon us, the pediatric neurosurgical consultants, as their primary caretakers. Pediatric neurosurgery patients also come with families and loved ones whose fear, joy, despair, and elation we share on a daily basis. Yet, all of this is done while guiding therapies, performing operations, or just holding a small hand in a moment of pain. Working these past years as Editorin-Chief of Pediatric Neurosurgery, I contend that the greatest constant we experience in our neurosurgical journeys is an unending pathway of change and evolution. I have been privileged to work with the talented, efficient, and caring Karger Publishing company that has overseen the evolution of Pediatric Neurosurgery from a typewriter and paper journal to the current version, whose articles are available on the internet, whose manuscripts are reviewed and edited electronically, yet whose pages can be browsed in print form in our University libraries. The Karger family's dedication to publishing high-quality and high-impact journals, not least of which is Pediatric Neurosurgery, is remarkable. Their support of our journal has been outstanding and has provided a growing and evolving independent voice for controversial topics in pediatric neurosurgery. We are able to publish innovative clinical approaches side by side with highimpact research data, and, in a very important way, we have provided a home for high-quality articles from emerging pediatric neurosurgery programs around the globe. I have worked with an enthusiastic editorial board these past years that has viewed every manuscript review as an opportunity to identify the strongest portion of each contribution and to strive to improve its analysis, presentation, and ultimate message. Most importantly, I have witnessed an evolution in our authors and readership as Pediatric Neurosurgery has become a truly multinational journal that readily reviews and accepts material from both the Old and the New World, while providing an easily accessible portal to pediatric neurosurgical knowledge for practitioners and scholars alike. Change is also welcomed in our journal, and as my work with it transitions, I look forward to the innovation and excitement that Tim George, our next Editor, will bring to Pediatric Neurosurgery. Though many might crave stability, it seems we are forever at a crossroads in pediatric neurosurgery, be it in our practice patterns, our educational systems, or in our research endeavors. Rather than a cause for concern, our times of uncertainty must be our greatest strength: during such times we are forced to refine our clinical care and refocus our path to the future through research and education. With that thought in mind, we are proud of the impact Pediatric Neurosurgery has had in our specialty and I, for one, look forward to hearing its clear and everevolving voice in the years to come.

David M. Frim, MD Chicago, Ill., USA

June 2013

\section{KARGER}

E-Mail karger@karger.com

www.karger.com/pne (c) 2013 S. Karger AG, Basel

1016-2291/12/0485-0269\$38.00/0 